\title{
ANALISIS PENYETORAN, PELAPORAN, DAN PENCATATAN PPH FINAL PASAL 4 AYAT (2) ATAS BUNGA DEPOSITO DAN TABUNGAN NASABAH PADA BPR PRISMA DANA CABANG AMURANG
}

\author{
Marchella Tiara Muhea ${ }^{1}$ \\ Jantje J. Tinangon ${ }^{2}$ \\ Inggriani Elim ${ }^{3}$ \\ Fakultas Ekonomi dan Bisnis, Jurusan Akuntansi \\ Universitas Sam Ratulangi, Manado \\ Email : ${ }^{1}$ marchella_muhea@yahoo.com \\ ${ }^{2}$ jantjetinangon447@gmail.com \\ [nggriani_elim@yahoo.com
}

\begin{abstract}
The income tax is the largest source of income in taxes. The income tax is a tax impossed on the income received by the taxpayer in the tax year. One type of income tax is the Final Income Tax Article 4 Paragraph 2 on interest deposit and customer's savings. The purpose of this research was to determine the suitability of depositing, reporting, and recordkeeping Final Income Tax Article 4 (2) on interest deposits and savings at BPR Prisma Dana, branch Amurang with tax regulations. The method used in this research is descriptive analysis. The results of this study indicates that BPR Prisma Dana, branch Amurang already done the tax obligation in cutting, depositing, and report final income tax article 4 paragraph 2 on deposit and saving account, but there is a delay in depositing and reporting taxation. Instead, the payment and reporting can be done on time, so as not to incur administrative fines.

Keywords: payment, reporting, interest on deposits, savings
\end{abstract}

\section{Latar Belakang}

PENDAHULUAN

Indonesia sebagai salah satu Negara berkembang membutuhkan ketersediaan dana yang memadai untuk melakukan pembangunan di segala bidang. Sumber pemasukan terbesar untuk kas Negara adalah dari sektor pajak, disamping pendapatan-pendapatan lainnya seperti hasil pertambangan dan usaha-usaha milik negara. Manfaatnya tidak akan diterima secara langsung, melainkan dapat dilihat dan dinikmati dalam kehidupan sehari-hari. Untuk itu pemerintah memiliki prioritas yang tinggi dalam memaksimalkan atau menggenjot penerimaan dari sektor pajak.

Pemerintah menetapkan aturan baru denganmengganti aturan lama mengenai sistem pemungutan pajak dari official assessment system menjadi self assessment system. Dalam self assessment system, wajib pajak diberikan kepercayaan dan wewenang untuk menghitung besarnya pajak yang terutang dan melaporkan secara teratur jumlah pajak terutang dan yang telah dibayar sebagaimana peraturan undangundang perpajakan yang berlaku.

Wajib pajak badan berkewajiban untuk memotong, menyetor, dan melaporkan setiap pajak terutang termasuk PPh Final Pasal 4 ayat (2). Pajak Penghasilan pasal 4 ayat (2) adalah pemotongan atau pemungutan pajak yang bersifat final, yang dikenakan atas beberapa jenis penghasilan tertentu sebagaimana sudah diatur dalam UU No. 36 tahun 2008 pasal 4 ayat (2). Setiap nasabah yang mendapatkan penghasilan dari bunga deposito dan tabungan akan dikenai potongan PPh Final pasal 4 ayat (2) sebesar $20 \%$. Tingginya tarif pajak dan jumlah nasabah yang setiap tahun mengalami peningkatan membuat pajak atas bunga deposito dan tabungan menjadi salah satu pajak yang dapat diperhitungakan untuk dipungut oleh pemerintah agar memaksimalkan pendapatan Negara dari sektor perpajakan.

Yang menjadi objek dalam penelitian ini adalah BPR Prisma Dana cabang Amurang. Merupakan salah satu lembaga keuangan yang memberikan layanan simpanan dan produk pembiayaan untuk 
memenuhi kebutuhan dana bagi pengusaha golongan mikro, kecil, dan menengah. BPR Prisma Dana cabang Amurang merupakan subjek pajak badan yang memiliki kewajiban di bidang perpajakan yakni memotong, menyetor, dan melaporkan utang pajak sendiri sesuai ketentuan perpajakan yang berlaku. Dalam kaitannya dengan akuntansi pihak bank akan mencatat setiap transaksi yang berkaitan dengan utang PPh Final Pasal 4 ayat 2. Dengan diterapkannya self assessment system tidak menutup kemungkinan terjadi kesalahan baik dalam pemotongan pajak sampai pencatatan yang harus disesuaikan dengan aturan akuntansi. Berdasarkan beberapa hal di atas, maka penulis tertarik mengambil judul skripsi tentang "Analisis Penyetoran, Pelaporan, dan Pencatatan PPh Final Pasal 4 Ayat (2) atas Bunga Deposito dan Tabungan Nasabah Pada BPR Prisma Dana Cabang Amurang."

\section{Tujuan Penelitian}

Tujuan dari penelitian ini adalah untuk mengetahui kesesuaian antara penyetoran, pelaporan, dan pencatatan PPh Final pasal 4 ayat (2) atas bunga deposito dan tabungan nasabah pada PT. BPR Prisma Dana cabang Amurang dengan Ketentuan Perpajakan yang berlaku.

\section{TINJAUAN PUSTAKA}

\section{Konsep Akuntansi Pajak}

Menurut Supriyanto (2011:2-3)akuntansi pajak adalah suatu proses pencatatan, penggolongan, dan pengikhtisaran suatu transaksi keuangan kaitannya dengan kewajiban perpajakan dan diakhiri dengan pembuatan laporan keuangan fiskal sesuai dengan ketentuan dan peraturan perpajakan yang terkait sebagai dasar pembuatan surat pemberitahuan tahunan.

\section{Konsep Perpajakan}

Membayar pajak berarti menyerahkan sebagian kekayaan milik pribadi kepada Negara untuk dikelolah demi keperluan bersama. Sebagaimana yang tercantum dalam Undang-Undang No. 28 tahun 2007 pasal 1 tentang Ketentuan Umum dan Tatacara Perpajakan mengenai pengertian pajak ialah kontribusi wajib kepada Negara yang terutang oleh orang pribadi atau badan yang bersifat memaksa berdasarkan Undang-Undang, dengan tidak mendapatkan imbalan secara langsung dan digunakan untuk keperluan Negara bagi sebesar-besarnya kemakmuran rakyat.

\section{Sistem Pemungutan Pajak}

Sistem pemungutan pajak menurut Mardiasmo (2011:7) yang dikenal di Indonesia ada tiga, yaitu:

1. Official Assessment System

Adalah sistem pemungutan yang memberi wewenang kepada pemerintah (fiskus) untuk menentukan besarnya pajak yang terutang oleh wajib pajak.

2. Self Assessment System

Adalah sistem pemungutan pajak yang memberi wewenang kepada wajib pajak untuk menentukan sendiri besarnya pajak terutang.

3. With Holding System

Adalah sistem pemungutan pajak yang memberi wewenang kepada pihak ketiga (bukan fiskus dan bukan wajib pajak yang bersangkutan) untuk menentukan besarnya pajak yang terutang oleh wajib pajak.

\section{Pajak Penghasilan}

Sebagaimana yang tercantum dalam pasal 1 Undang-undang Pajak Penghasilan, menyatakan bahwa Pajak Penghasilan dikenakan terhadap subjek pajak atas penghasilan yang diterima dalam tahun pajak. Oleh sebab itu, pajak penghasilan melekat pada subjeknya. Menurut Resmi (2011: 74), pajak Penghasilan adalah pajak yang dikenakan terhadap subjek pajak penghasilan yang diterima atau diperoleh dalam satu tahun pajak. 


\section{PPh Pasal 4 ayat (2)}

Atas dasar penyederhanaan, keadilan dan untuk meningkatkan kepatuhan wajib pajak maka berdasarkan pertimbangan beberapa hal tersebut diberlakukan Pajak Penghasilan Final atau yang dikenal dengan PPh Final Pasal 4 ayat (2). Pajak Penghasilan bersifat final merupakan pajak penghasilan yang pengenaannya sudah final (berakhir) sehingga tidak dapat dikreditkan (dikurangkan) dari total Pajak Penghasilan terutang pada akhir tahun pajak (Resmi, 2011: 139).

\section{Dasar Hukum PPh Final Pasal 4 Ayat 2 Atas Bunga Deposito dan Tabungan}

1. PP No. 131 Tahun 2000

Aturan ini berlaku sejak 1 Januari 2001 menggantikan PP No. 51 tahun 1994 tentang pajak penghasilan atas bunga deposito dan tabungan serta diskonto SBI.Dalam aturan ini memuat tentang objek pajak, wajib pajak, pihak pemotong, tarif pajak, pengecualian dari pemotongan pajak, dan sebagainya.

\section{KMK-51/KMK.04/2001}

Aturan ini berlaku sejak Januari 2001 menggatikan KMK No. 652/KMK.04/1994 tentang pemotongan pajak penghasilan atas bunga deposito dan tabungan serta diskonto SBI. Aturan ini memuat tentang objek pajak, wajib pajak, pihak pemotong, tarif pajak, dan pengecualian dari pemotongan pajak sebagaimana yang telah diatur juga dalam PP No. 131 Tahun 2000

\section{SE-01/PJ.43/2001}

Surat edaran ini diterbitkan oleh Direktur Jenderal Pajak tentang pengawasan pemotongan, penyetoran dan pelaporan PPh Final atas bunga deposito dan tabungan serta diskonto BI. Surat edaran ini diterbitkan untuk kemudian diteruskan dan dikonfirmasikan kepada bank-bank yang terdapat di masingmasing wilayah kerja Kantor Pelayanan Pajak.

\section{Objek PPh Final Pasal 4 ayat (2) Atas Bunga Deposito dan Tabungan}

Penghasilan berupa bunga deposito dan tabungan serta diskonto Sertifikat Bank Indonesia termasuk bunga yang diterima atau diperoleh dari deposito dan tabungan yang ditempatkan di luar negeri melalui bank yang didirikan atau bertempat kedudukan di Indonesia atau cabang bank luar negeri di Indonesia. Natalia \& Anastasia (2014), untuk bank deposito adalah salah satu sumber jangka panjang utama, untuk nasabah deposito adalah alat untuk pengamanan dan peningkatan tabungan. Sedangkan, tabungan adalah simpanan pada bank dengan nama apapun, yang penarikannya dilakukan menurut syarat-syarat tertentu yang ditetapkan oleh masing-masing bank.

\section{Tarif PPh Final Pasal 4 ayat (2) Atas Bunga Deposito dan Tabungan}

Penghasilan yang diperoleh dari bunga deposito dan tabungan yang ditempatkan di luar negeri melalui bank yang didirikan di Indonesia atau cabang bank luar negeri di Indonesia wajib dipotong pajak sebesar 20\%. Untuk wajib pajak luar negeri selain Bentuk Usaha Tetap, dipotong pajak sebesar 20\% atau sesuai ketentuan dalam Perjanjian Penghindaran Pajak Berganda (P3B).

\section{Bank Perkreditan Rakyat}

Muljono (2009: 397) mendefinisikan bank merupakan lembaga yang berperan sebagai perantara keuangan antara pihak yang memiliki dana dan pihak yang memerlukan dana. Dalam UU tentang Perbankan, Bank Perkreditan Rakyat dapat menjalankan usaha meliputi:

1. Menghimpun dana dari masyarakat dalam bentuk simpanan berupa deposito berjangka, tabungan, dan/atau bentuk lainnya yang dipersamakan dengan itu

2. Memberikan kredit 
3. Menyediakan pembiayaan dan penempatan dana berdasarkan prinsip syariah sesuai ketentuan yang ditetapkan oleh Bank Syariah

4. Menempatkan dananya dalam bentuk Sertifikat Bank Indonesia (SBI), deposito berjangka, sertiikat deposito, dan/atau tabungan pada bank lain

Sedangkan usaha yang tidak dapat dijalankan oleh Bank Perkreditan rakyat adalah sebagai berikut.

1. Menerima simpanan dalam bentuk giro dan ikut serta dalam lalulintas pembayaran

2. Melakukan kegiatan usaha dalam valuta asing

3. Melakukan penyertaan modal

4. Melakukan usaha perasuransian

5. Melakukan usaa lain diluar kegiatan usaha yang telah ditetapkan dalam Undang-undang

\section{Penelitian Terdahulu}

Tangka (2014) mengambil judul skripsi Analisis perhitungan PPh Final pasal 4 ayat (2) atas bunga deposito dan tabungan nasabah pada PT. Bank Rakyat Indonesia (persero),Tbk cabang Manado. Bertujuan untuk mengetahui bagaimana perhitungan bunga serta pemotongan pajak penghasilan final atas bunga tabungan dan deposito nasabah pada PT. Bank Rakyat Indonesia (persero),Tbk cabang Manado. Metode yang digunakan adalah analisis deskriptif. Hasil penelitian yaitu perhitungan pajak penghasilan final pasal 4 ayat (2) atas bunga deposito dan tabungan nasabah oleh PT. Bank Rakyat Indonesia (persero),Tbk cabang Manado telah sesuai dengan peraturan perundang undangan yang berlaku. Yunita (2013) mengambil judul skripsi Analisis Penerapan Pajak Dengan Withholding Tax System Terhadap Pajak Penghasilan Pasal 4 Ayat (2) Pada PT. Bank OCBC NISP Kota Palembang. Tujuan penlitian yaitu Menganalisis penerapan pemotongan, penyetoran dan pelaporan, kendala - kendala serta upaya yang dilakukan terhadap Withholding Tax System pada PPh Pasal 4 Ayat 2 pada Bank OCBC NISP Palembang. Metode yang digunakan adalah Analisis deskriptif. Hasil penelitian yaitu Bank OCBC NISP telah melaksanakan kewajiban perpajakannya dengan baik dan sesuai dengan peraturan perpajakan yang berlaku, hanya saja masih perlu melakukan integrasi pada saat penginputan suku bunga deposito yang jatuh tempo agar tidak terdapat kesalahan.

\section{METODE PENELITIAN}

\section{Jenis Penelitian}

Definisi penelitian deskriptif menurut Restu (2010: 47) adalah penelitian untuk memberikan gambaran secara sistematis tentang situasi, permasalahan, fenomena, layanan atau program, ataupun menyediakan informasi tentang misalnya, kondisi kehidupan suatu masyarakat pada suatu daerah, tatacara yang berlaku dalam masyarakat serta situasi-situasi, sikap, pandangan, proses yang sedang berlangsung, pengaruh dari suatu fenomena, pengukuran yang cermat tentang fenomena dalam masyarakat.

\section{Tempat dan Waktu Penelitian}

Penelitian ini dilakukan di PT. BPR Prisma Dana cabang Amurang yang berlokasi di Jl. Trans Sulawesi, kel. Buyungon Minahasa Selatan. Waktu penelitian dilakukan pada bulan Maret sampai April 2016.

\section{Prosedur Penelitian}

Prosedur penelitian yang dilakukan adalah sebagai berikut:

1. Merumuskan masalah dan menetapkan judul penelitian

Peneliti melakukan identifikasi masalah yang hendak diteliti dan mencari informasi pendukung dengan melakukan studi kepustakaan lewat Undang-undang, buku-buku, dan jurnal penelitian terdahulu yang dapat menguatkan judul yang dipilih. 


\section{Pengajuan permohonan penelitian}

Peneliti mengajukan Surat Permohonan Penelitian dari Fakultas kepada Pimpinan Cabang BPR Prisma Dana Amurang untuk diterima dan ditanda tangani oleh Pimpinan Cabang.

3. Pengumpulan data

Tahap pengumpulan data dilakukan dengan observasi langsung ke BPR Prisma Dana cabang Amurang. Mewawancarai Kasie Umum, SDM, dan Akuntansi BPR Prisma Dana cabang Amurang dan meminta data yang dibutuhkan untuk menunjang penelitian.

4. Menganalisis data

Berdasarkan data yang diperoleh dari pihak BPR Prisma Dana cabang Amurang selanjutnya dilakukan analisis terhadap data-data tersebut dan melakukan diskusi bersama dosen pembimbing I dan dosen pembimbing II.

5. Menarik kesimpulan.

Berdasarkan data yang telah diolah dan didiskusikan bersama, penulis dapat merangkumkan hasil penelitian dalam bentuk kesimpulan.

\section{Jenis Data}

Data dalam penelitian menurut Sujarweni yang dikutip oleh Sutrimo (2015), merupakan sekumpulan informasi yang diperoleh dari lapangan dan digunakan untuk bahan penelitian. Dalam penelitian ini penulis menggunakan jenis data kualitatif dari sumber primer dan sumber sekunder.

\section{Sumber Data}

Dalam hal ini peneliti memperoleh data primer dengan wawancara langsung dengan Kasie Umum, SDM, dan Akuntansi BPR Prisma Dana cabang Amurang. Sedangkan untuk data sekunder berasal dari catatan dan dokumen resmi yang diberikan oleh pihak BPR Prisma Dana cabang Amurang.

\section{Metode Analisis Data}

Metode analisis data yang digunakan adalah metode deskriptif. Dimana teknik yang akan dilakukan yaitu;

1. Mengumpulkan data dan informasi yang dibutuhkan.

2. Mengetahui peraturan Perpajakan yang berlaku terkait pajak atas bunga deposito dan tabungan nasabah.

3. Menguraikan perhitungan dan pemotongan atas bunga deposito dan tabungan nasabah.

4. Menganalisis tahapan penyetoran, pelaporan, dan pencatatan PPh Final pasal 4 ayat 2 apakah sudah sesuai dengan ketentuan perpajakan yang berlaku.

5. Menarik kesimpulan dari penelitian yang telah dilakukan.

\section{HASIL PENELITIAN}

\section{GambaranUmum BPR Prisma Dana Cabang Amurang}

Bank Prisma Dana menjadiBank Perkreditan Rakyat andalan masyarakat Sulawesi Utara. Hal ini dibuktikan dengan tercatat sebagai BPR terbesar di Provinsi Sulawesi Utara dengan jumlah kantor cabang serta kantor kas dan pos pelayanan yang tersebar hampir di sejumlah wilayah di Sulawesi Utara. Total ada 12 kantor BPR Prisma dana yang siap melayani masyarakat umum dan sektor UMKM. Salah satunya adalah kantor cabang yang ada di Kota Amurang, lebih tepatnya beralamatkan di Jl. Trans Sulawesi Kelurahan Buyungon, Kabupaten Minahasa Selatan. 
Prisma Dana cabang Amurang adalah kantor cabang ke lima milik PT. BPR Prisma Dana yang diresmikan sejak tanggal 09 Mei 2011. Bank Prisma Dana cabang Amurang melayani transaksi dana, menyalurkan kredit kepada sektor UMKM, dan jasa lainnya seperti membantu masyarakat dalam membayar tagihan rekening listrik dan telepon, serta membantu dalam pengiriman uang melalui western union. BPR Prisma Dana cabang Amurang secara efektif dan efisien terus berupaya meningkatkan kinerja dan kualitas pelayanan kepada nasabah guna mencapai satu tujuan yaitu menjadi Bank yang profesional, besar, kuat dan sehat. Peningkatan jumlah nasabah setiap tahunnya membuktikan bahwa BPR Prisma Dana cabang Amurang berkualifikasi untuk bersaing dengan Bank umum dan BPR lainnya untuk menjadi bank yang dapat diandalkan dan dipercayai nasabah sebagai tempat menabung dan berinvestasi serta mengembangkan usahanya. Simpanan nasabah di BPR Prisma Dana cabang Amurang lebih aman karena dijamin oleh Lembaga Penjamin Simpanan.

Pimpinan cabang saat ini adalah Bapak Christian Piri, SE. Total karyawan yang bekerja di BPR Prisma Dana cabang Amurang mencapai 20 orang dengan manajemen yang solid dan bekerja profesional, yang berkomitmen memberikan pelayanan terbaik untuk kepuasan nasabahnya serta meningkatkan kualitas SDM karyawannya.

\section{Pemotongan PPh Final Pasal 4 Ayat 2 Atas Bunga Deposito dan Tabungan}

Tabel 4.1 suku bunga BPR Prisma Dana

\begin{tabular}{lc}
\hline \multicolumn{1}{c}{ Jenis Produk } & Suku Bunga \\
\hline Tabungan & $4 \%$ \\
\hline Deposito 1 bulan & $8 \%$ \\
\hline Deposito 3 bulan & $8,5 \%$ \\
\hline Deposito 6 bulan & $9 \%$ \\
\hline Deposito 12 bulan & $9,5 \%$ \\
\hline
\end{tabular}

Sumber: BPR Prisma Dana Cabang Amurang

a. Perhitungan PPh Final pasal 4 ayat 2 bunga deposito nasabah $\mathrm{M}$ diambil dari sampel pada bulan Desember 2015, dengan nominal deposito sebesar Rp90.000.000,00 (sembilan puluh juta rupiah). Atas pendapatan bunga yang diterima nasabah akan dipotong pajak sebesar $20 \%$.

Rumus perhitungan pajak: PPh Final Pasal 4 Ayat $2=20 \% \mathrm{x}$ bunga deposito

Berdasarkan rumus di atas, perhitungan bunga deposito 1 bulan dan pemotongan PPh Final pasal 4 ayat 2 adalah sebagai berikut.

$$
\begin{array}{lll}
\text { Pendapatan bunga deposito } & =\mathrm{Rp} 90.000 .000 \times 8 \% & =\mathrm{Rp} 7.200 .000 \\
\mathrm{PPh} \text { Final pasal } 4 \text { ayat } 2 & =\mathrm{Rp} 7.200 .000 \times 20 \% & =\mathrm{Rp} 1.440 .000 \\
\text { Pendapatan bunga bersih } & =\mathrm{Rp} 7.200 .000-\mathrm{Rp} 1.440 .000 & =\mathrm{R} 55.760 .000
\end{array}
$$

Dalam pembukuan pihak Bank akan mencatat deposito di sebelah kredit sebagai utang yang harus dilunasi. Pada saat pengakuan beban bunga, pihak Prisma Dana akan mencatatnyasebagai berikut.

Beban bunga

Utang bunga

PPh Pasal 4 ayat 2

$$
\text { Rp7.200.000,00 }
$$

$$
\operatorname{Rp5} .760 .000,00
$$

$$
\text { Rp1.440.000,00 }
$$

b. Perhitungan PPh Final pasal 4 ayat 2 bunga tabungan menggunakan metode perhitungan Saldo harian. Bunga tabungan dihitung berdasarkan saldo harian dalam bulan berjalan kemudian akan 
dijumlahkan pada akhir bulan. Berikut perhitungan berdasarkan transaksi rekening nasabah $\mathrm{R}$ yang diambil pada bulan Oktober 2015.

Table 4.2Transaksirekening nasabah R bulanOktober 2015

\begin{tabular}{lccc}
\hline Tanggal & Setoran & Penarikan & Saldo \\
\hline $01-10-2015$ & & Rp18.000.000 \\
\hline $05-10-2015$ & Rp5.000.000 & & Rp23.000.000 \\
\hline $10-10-2015$ & & Rp1.500.000 & Rp21.500.000 \\
\hline $17-10-2015$ & Rp2.000.000 & Rp19.500.000 \\
\hline $26-10-2015$ & & Rp750.000 & Rp18.750.000 \\
\hline
\end{tabular}

Sumber: BPR Prisma Dana Cabang Amurang

\begin{tabular}{|c|c|c|c|c|}
\hline Bunga Tabungan & $=$ & (Rp. $18.000 .000 \times 4 \% / 365) \times 4$ hari & $=$ & Rp7.890 \\
\hline & $=$ & (Rp. 23.000.000 x 4\% / 365) x 5 hari & $=$ & Rp12.602 \\
\hline & $=$ & (Rp. 21.500.000 x 4\% / 365) x 7 hari & $=$ & Rp16.493 \\
\hline & $=$ & (Rp. 19.500.000 x 4\% / 365) x 9 hari & $=$ & Rp19.232 \\
\hline & $=$ & (Rp. $18.750 .000 \times 4 \% / 365) \times 5$ hari & $=$ & $\underline{\mathrm{Rp} 10.273}$ \\
\hline & & & & Rp66.490 \\
\hline
\end{tabular}

PPh Final pasal 4 ayat (2) $=20 \% \times$ bunga tabungan

$=\quad 20 \% \times \mathrm{Rp} 66.490$

$=\operatorname{Rp} 13.298$

PendapatanbungaNetto $\quad=\quad$ Rp66.490-Rp13.298

$=\quad \operatorname{Rp} 53.192$

Pembayaran bunga dilakukan setiap akhir bulan berdasarkan jumlah bunga setiap hari, yang dihitung dengan metode saldo hariandan akan ditransfer ke rekeningmasing-masing nasabahnya. Bank Prisma Dana akan membuat jurnal sebagai berikut.

Beban bunga $\quad$ Rp66.490

Utang bunga

PPh Pasal 4 ayat 2
Rp53.192

Rp13.298

\section{PenyetorandanPelaporanPPh Final Pasal 4 Ayat 2 atasBungaDepositodan Tabungan Nasabah}

Setiap bulannya rekening nasabah akan dipotong pajak atas penghasilan bunga deposito dan tabungan yang dilakukan secara otomatis oleh sistem komputer, kemudian pihak BPR Prisma Dana cabang Amurang menyetorkan pajak yang dipotong dengan menggunakan Surat Setoran Pajak (SSP) PPh Pasal 4 Ayat (2) kekas Negara melalui Bank Negara Indonesia (BNI)sebagai Bank persepsi. Selanjutnya, kewajiban BPR Prisma Dana cabang Amurang adalah melaporkan pajak yang telah disetor melalui BNI dengan menggunakan SPT Masa PPh Pasal 4 Ayat (2) ke Kantor Pelayanan Pajak (KPP) Pratama Kotamobagu tempat wajib pajak terdaftar. Dalam hal ini BPR Prisma Dana cabang Amurang melakukan pelaporan pajak ke Kantor Pelayanan Penyuluhan dan Konsultasi Perpajakan (KP2KP) Amurang. KP2KP Amurang diberikan wewenang sebatas menerima pelaporan pajak oleh wajib pajak, sedangkan untuk penyetoran pajak dilakukan melalui Bank persepsi. Pelaporan PPh Final pasal 4 ayat 2 dengan menggunakan SPT Masa manual (hardcopy) dan dilampirkan juga bukti pemotongan, cetak bukti 
penerimaan Negara, dan SSP. BPR Prisma Dana cabangAmurang akan menerima bukti penerimaan suratdari KP2KP Amurang sebagai tanda bahwa telah melaporkan PPh Final Pasal 4 ayat 2.

Tabel 4.3Pelaksanaan kewajiban Perpajakan BPR Prisma Dana cabang Amurang bulan September sampai Desember 2015

\begin{tabular}{cccccc}
\hline Masa Pajak & $\begin{array}{c}\text { Nilai Objek } \\
\text { pajak (Rp) }\end{array}$ & Tarif & $\begin{array}{c}\text { PPh yang } \\
\text { dipotong (Rp) }\end{array}$ & Penyetoran & Pelaporan \\
\hline $09 / 09 / 2015$ & 45.678 .085 & $20 \%$ & 9.135 .617 & $10 / 11 / 2015$ & $18 / 11 / 2015$ \\
\hline $10 / 10 / 2015$ & 46.642 .155 & $20 \%$ & 9.328 .431 & $12 / 11 / 2015$ & $22 / 11 / 2015$ \\
\hline $11 / 11 / 2015$ & 56.335 .545 & $20 \%$ & 11.267 .109 & $11 / 12 / 2015$ & $18 / 12 / 2015$ \\
\hline $12 / 12 / 2015$ & 55.182 .855 & $20 \%$ & 11.036 .571 & $08 / 01 / 2016$ & $15 / 01 / 2016$
\end{tabular}

\section{Sumber : BPR Prisma Dana Cabang Amurang}

Pihak Bank akan mencatat setiap transaksi penyetoran PPh Final pasal 4 ayat 2 yang telah dilakukan, misalkan transaksi bulan Oktober sampai Desember akan dibuat jurnal sebagai berikut :

10/11/2015 Utang PPh Pasal 4 ayat 2

Kas/Bank

12/11/2015 Utang PPh Pasal 4 ayat 2

Kas/Bank

11/12/2015 Utang PPh Pasal 4 ayat 2

Kas/Bank

08/01/2015 Utang PPh Pasal 4 ayat 2

Kas/Bank
Rp9.135.617

Rp9.135.617

Rp9.328.431

Rp9.328.431

Rp11.267.109

Rp11.267.109

Rp11.036.571

Rp11.036.571

\section{Pembahasan}

Dari hasil penelitian yang diperoleh, sesuai dengan PP No. 131 Tahun 2000 BPR Prisma Dana cabang Amurang melakukan pemotonganPPh Final pasal 4 ayat 2 atas bunga deposito dan tabungan nasabah dimana jumlah deposito dan tabungan yang nominalnya melebihi Rp7.500.000,00 (tujuh juta lima ratus ribu rupiah) akan dikenai pajak sesuai tarif sebesar $20 \%$ dari jumlah bruto.

Penyetoran dan pelaporan yang dilakukan BPR Prisma Dana cabang Amurang mengalami sedikit keterlambatan dari batas waktu yang telah ditentukan, yaitu penyetoran pajak melalui Bank selambatlambatnya tanggal 10 bulan berikutnya setelah masa pajak berakhir dan batas waktu pelaporan paling lama tanggal 20 bulan berikutnya setelah masa pajak berakhir. Berdasarkan data yang diperoleh pada tabel 4.3, dalam Surat Setoran Pajak (SSP) masa pajak bulan September, Oktober, dan November belum sesuai dengan batas waktu penyetoran dan pelaporan pajak. Sedangkan untuk penyetoran dan pelaporan pajak bulan Desember sudah sesuai dengan batas waktu yang ditentukan.

Hasil penelitian ini menunjukan hasil yang sama dengan penelitian yang dilakukan oleh Mokoagow (2015) pada PT. Bank Sulut Cabang Kotamobagu yaitu perhitungan bunga tabungan menggunakan metode saldo harian dan tarif sesuai aturan yaitu $20 \%$ dari pendapatan bunga yang diperoleh nasabah. Sedangkan Penelitian yang dilakukan Tangka (2014) pada PT. Bank Rakyat Indonesia (PERSERO) Tbk menggunakan metode perhitungan yang berbeda yaitu dengan metode perhitungan saldo terendah. Penelitian yang dilakukan Yunita (2013) PT. Bank OCBC NISP Kota Palembang menunjukan perbedaan 
dalam sstem pemungutan pajak PPh Final Pasal 4 Ayat 2, yaitu menggunakan sistem pemungutan pajak dengan Witholding System.

\section{Kesimpulan}

Kesimpulan dari penelitian ini adalah sebagai berikut.

1. BPR Prisma Dana cabang Amurang memotong, menyetor, dan melaporkan PPh Final pasal 4 ayat (2) atas penghasilan bunga deposito dan tabungan nasabah sesuai dengan aturan dalam PP No. 131 Tahun 2000 dan KMK No.51/KMK.04/2001.

2. Jumlah bunga deposito dan tabungan nasabah pada BPR Prisma Dana cabang Amurang yang nominalnya lebih dari Rp7.500.000 (tujuh juta lima ratus ribu rupiah) dikenakai Pajak PPh Final Pasal 4 Ayat (2) sebesar $20 \%$.

3. Perhitungan bunga tabungan pada BPR Prisma Dana cabang Amurang menggunakan metode perhitungan saldo harian, dimana bunga dihitung berdasarkan saldo setiap hari yang dijumlahkan setiap akhir bulan dan secara otomatis akan ditambahkan ke rekening nasabah melalui sistem komputerisasi.

4. Prisma Dana cabang Amurang akan menyetorkan pajak yang dipotong melalui Bank Negara Indonesia (BNI) dan melaporkan pajak yang telah disetorkan ke KP2KP Amurang dengan melampirkan SSP, SPT Masa PPh Final pasal 4 ayat 2, cetak bukti penerimaan Negara, dan bukti pemotongan.

5. Berdasarkan data yang diperoleh penyetoran dan pelaporan pada bulan September, Oktober, dan November belum sesuai dengan aturan perpajakan mengenai batas waktu, dimana mengalami sedikit keterlambatan dari batas waktu yang ditentukan. Sedangkan untuk penyetoran dan pelaporan pajak bulan Desember sudah sesuai dengan aturan perpajakan.

\section{Saran}

Saran dari penulis sebaiknya pihak BPR Prisma Dana cabang Amurang selalu memperhatikan waktu penyetoran dan pelaporan pajak untuk tidak melewati batas waktu yang ditentukan agar terhindar dari denda administrasi. Dan diharapkan juga pihak BPR Prisma Dana cabang Amurang terus mempertahankan kualitas pelayanan yang baik dan lebih meningkatkan kinerja karyawan agar selalu dipercaya oeh masyarakat dan tetap menjadi Bank Perkreditan Rakyat andalan dan nomor satu di Sulawei Utara.

Mardiasmo. 2011. Perpajakan (Rev). Yogyakarta: Andi

Mongkoagow, Wita. 2015. Analisis Perhitungan PPh Final Pasal 4 ayat (2) atas Bunga Deposito dan Tabungan Nasabah pada PT. Bank Sulut cabang Kotamobagu. Jurnal Emba, Vol. 3 No. 3 ISSN 2303-11.http://ejournal.unsrat.ac.id/index.php/emba/article/viewFile/9617/9205.Diakses

Desember2015.

Muljono, Djoko. 2009. Akuntansi Pajak Lanjutan. Yogyakarta: Andi

Natalia \& Anastasia. 2014. Bank Deposits: Tax Regulation Of Conditions. Saint Petersburg State University .http://rep.polessu.by/bitstream/112/8328/1/34.pdf.Dikases April 2016

Republik Indonesia. 1998. UU No. 10 Tahun 1998 tentang Perubahan Atas Undang-Undang Nomor 7 tahun 1992 Tentang Perbankan

Republik Indonesia. 2000. Peraturan Pemerintah No. 131 Tahun 2000 tentang Pajak Penghasilan atas Bunga Deposito dan tabungan serta Diskonto Sertifikat Bank Indonesia, Jakarta.

Republik Indonesia. 2001. KMK- 51/KMK.04/2001tentang Pemotongan Pajak Penghasilan Atas Bunga Deposito dan Tabungan Serta Diskonto Sertifikat Bank Indonesia 
Republik Indonesia. 2001. SE-01/PJ.43/2001 tentang Pengawasan Pemotongan, Penyetoran dan Pelaporan PPh Final Atas Bunga Deposito dan Tabungan Serta Diskonto BI.

Republik Indonesia. 2007. UU No. 28 Tahun 2007 tentang Perubahan Ketiga Atas Undang-undang Nomor 6 Tahun 1983 tentang Ketentuan Umum dan Tatacara Perpajakan, Jakarta.

Republik Indonesia. 2008. Undang-Undang Republik Indonesia nomor 36 Tahun 2008 tentang Pajak Penghasilan, Jakarta.

Resmi, Siti. 2011. Perpajakan Teori dan Kasus. Jakarta: Salemba Empat

Supriyanto, Edy. 2011. Akuntansi Perpajakan. Yogyakarta: Graha Ilmu

Sutrimo R, Dewi. Evaluasi Pemotongan, Penyetoran, dan Pelaporan Pajak Penghasilan Pasal 23 Pada PT. Hutama Karya (Persero). Universitas Sam Ratulangi. Jurnal Berkala Ilmiah Efisiensi Volume 15 No. 13.http://ejournal.unsrat.ac.id/index.php/jbie/article/view/9350/8929. Diakses Maret 2016

Tangka, Irene S. 2014. Analisis Perhitungan PPh Final Pasal 4 ayat (2) atas Bunga Deposito dan Tabungan Nasabah pada PT. Bank Rakyat Indonesia (Persero), Tbk. Universitas Sam Ratulangi. Manado. Jurnal Emba, Vol.2 1174.http://ejournal.unsrat.ac.id/index.php/emba/article/view/6239/5764. Diakses Desember 2015. Hal. 203-213

Widi, Restu. 2010. Asas Metodologi Penelitian. Yogyakarta: Graha Ilmu

Yunita, Senli. 2013. Analisis Penerapan Pajak dengan Withoulding Tax System Terhadap Pajak Penghasilan Pasal 4 ayat 2 pada PT. Bank OCBC NISP Kota Palembang. Skripsi STIE MDP. Palembang

.http://eprints.mdp.ac.id/1167/1/Jurnal\%20Skripsi\%20Senli\%20\%282010210058\%29.pdf. Diakses Desember 2015 